\title{
DSMC Simulations of Apollo Capsule Aerodynamics for Hypersonic Rarefied Conditions
}

\author{
James N. Moss* Christopher E. Glass, ${ }^{\dagger}$ and Francis A. Greene ${ }^{\ddagger}$ \\ NASA Langley Research Center, Hampton, VA 23681-2199
}

\begin{abstract}
Direct simulation Monte Carlo (DSMC) simulations are performed for the Apollo capsule in the hypersonic low-density transitional flow regime. The focus is on flow conditions similar to that experienced by the Apollo 6 Command Module during the high altitude portion of its reentry. Results for aerodynamic forces and moments are presented that demonstrate their sensitivity to rarefaction; that is, for free molecular to continuum conditions. Also, aerodynamic data are presented that shows their sensitivity to a range of reentry velocity, encompasing conditions that include reentry from low Earth orbit, lunar return, and Mars return velocities $(7.7$ to $15 \mathrm{~km} / \mathrm{s})$. The rarefied results are anchored in the continuum regime with data from Navier-Stokes simulations.
\end{abstract}

\section{Nomenclature}

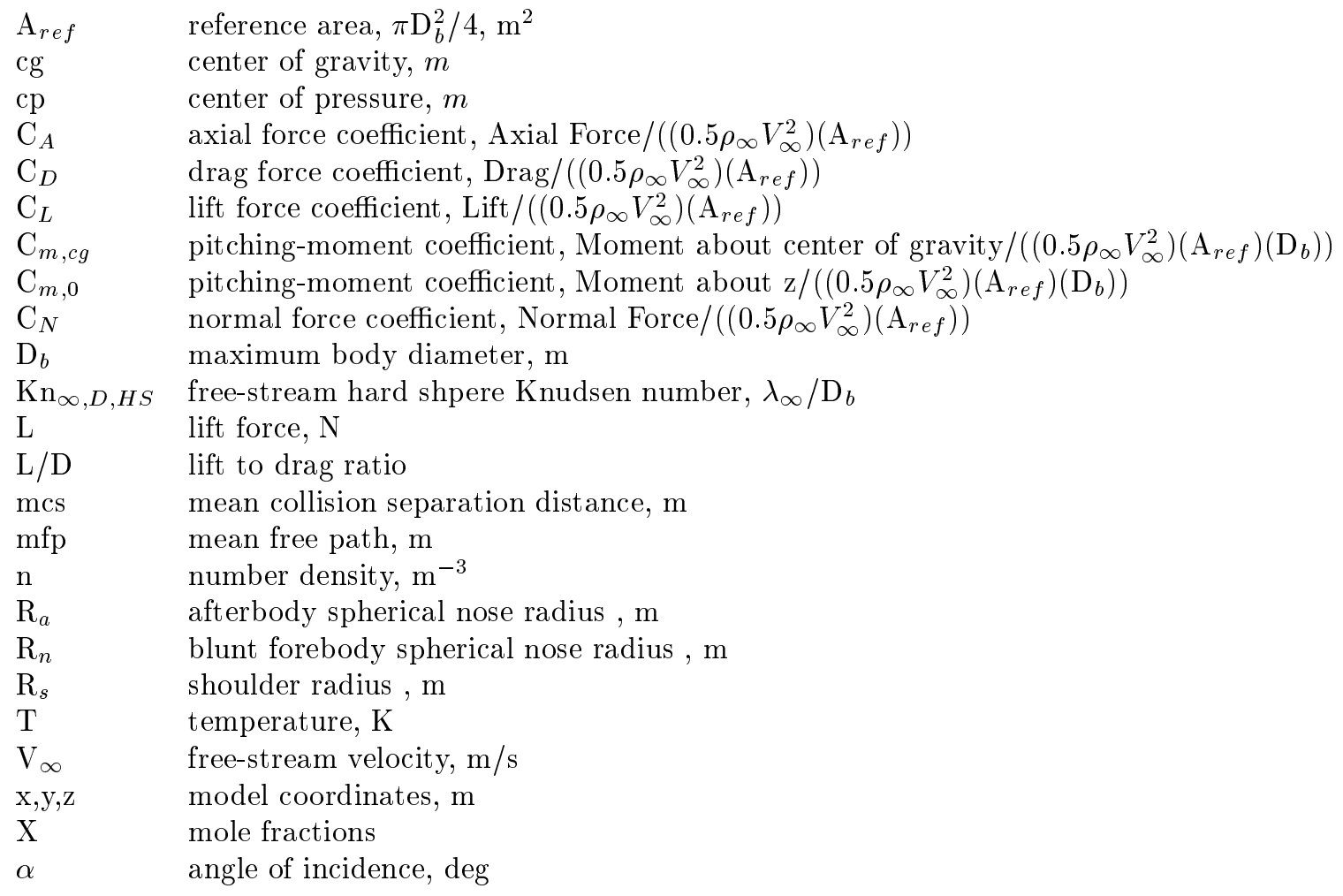

${ }^{*}$ Senior Research Engineer, Aerothermodynamics Branch, Mail Stop 408A, j.n.moss@larc.nasa.gov Fellow AIAA.

†Senior Research Engineer, Aerothermodynamics Branch, Mail Stop 408A, c.e.glass@larc.nasa.gov, AIAA Senior Member.

¥ Senior Research Engineer, Aerothermodynamics Branch, Mail Stop 408A, f.a.greene@larc.nasa.gov, AIAA Senior Member.

Copyright (C) 2006 by the American Institute of Aeronautics and Astronautics, Inc. The U.S. Government has a royalty-free license to exercise all rights under the copyright claimed herein for Governmental purposes. All other rights are reserved by the copyright owner. 


$\begin{array}{ll}\gamma & \text { inertial entry flight-path angle, deg } \\ \lambda_{\infty} & \text { mean free path in free stream, } \mathrm{m} \\ \rho & \text { density, } \mathrm{kg} / \mathrm{m}^{3}\end{array}$

\section{A. Subscripts}

W wall

$\infty \quad$ free stream

\section{Introduction}

The space capsule, ${ }^{1}$ eclipsed for decades by the more complex and costly shuttle, now appears likely to emerge as its successor. Realization of such a change is essentially assured with China's recent manned spaceflight successes and NASA's announced vision of a new space craft for human space exploration, the Crew Exploration Vehicle (CEV). China conducted a second successful manned spaceflight in October 2005 with the Shenzhou 6, a configuration that is an adaption of Russia's veteran Soyuz design. On September 19, 2005, NASA announced the findings of the Exploration Systems Architecture Study that recommended the use an Apollo-like capsule for the CEV design. The CEV is much larger than Apollo, almost twice the mass of the Apollo Command Module along with a much larger volume, and like Apollo, would be attached to a service module for life support and propulsion. Mission applications of the CEV include that of a low-Earth-orbit (LEO) version with a crew of six to the International Space Station, a lunar version that would carry a crew of four, and a Mars version that would carry a crew of six.

With commitments to evolve the CEV design(s) for LEO, lunar, and Mars missions, aerothermodynamic data bases will be generated utilizing computational and experimental (both ground-based and flight) resources. These new data bases along with an extensive capsule heritage, particularly that from Apollo (Refs. 2 to 6 , for example), will provide the basis for optimizing the CEV's design, with particular emphasis on safety, flexibility, and affordability. The current study focuses on the aerodynamics of the Apollo Command Module during the transitional portion of its reentry, from free molecular to near continuum continuum conditions. The primary focus is on flow conditions similar to those experienced by the Apollo 6 flight test, with a reentry velocity of $9.6 \mathrm{~km} / \mathrm{s}$. Numerical simulations for the transitional flow regime are made with the 3D DSMC code of Bird, ${ }^{7-9}$ called DS3V, and for the continuum regime with the 3D Navier-Stokes (NS) code of Gnoffo, ${ }^{10-12}$ called LAURA (Langley Aerothermodynamic Upwind Relaxation Algorithm). Results are presented that show the sensitivity of the capsule aerodynamics to rarefaction, velocity variations at an altitude of $105 \mathrm{~km}$, sensitivity to grid resolution, and chemistry model assumptions (number of species) at $85 \mathrm{~km}$ with the NS simulations. The DSMC results presented herein along with data from some recent studies $^{14,15}$ demonstrate available capability to address the transitional flow aerodynamics of capsules such as the CEV, a capability that did not exist when the Apollo Command Module design was evolved. The current results show that the lift and lift-to-drag coefficients increase substantially with decreasing rarefaction. Also, the location of the longitudinal center of pressure is very sensitive to the degree of rarefaction and the simulations show that the stable trim point for the Apollo capsule at $105 \mathrm{~km}$ altitude occurs at an incidence angle of -164 degrees rather than the nominal -25 degrees flown by Apollo 6; that is, the capsule is statically unstable for much, if not all, of the transitional flow regime, a result not that uncommon for capsules as discussed by Wilmoth et al. ${ }^{16}$ for the Stardust sample return capsule and Moss et al. ${ }^{17}$ for the Mars Pathfinder capsule. Results of the simulations for variations in free-stream velocity show that the changes in the aerodynamic coefficients with increasing velocity are similar to those incurred with increasing rarefaction; consistent with the correlations demonstrated by Wilhite et al. ${ }^{18}$ (Fig. 7, p 172) for the Shuttle Orbiter axial-force coefficients as a function of a viscous correlation parameter.

\section{Numerical Programs and Model Parameters}

\section{A. DSMC Analyses}

The DSMC program used in the current study is the DS3V program of Bird, ${ }^{7-9}$ a general 3D code that provides both time accurate unsteady flow and time-averaged steady flow simulations. A scalar version 
of this program was used in this study where all the simulations were made by using a $3.2 \mathrm{GHz}$ personal computer with a memory of $2.0 \mathrm{~GB}$. Molecular collisions are simulated with the variable hard sphere (VHS) molecular model. The Larsen-Borgnakke statistical mode ${ }^{13}$ controls the energy exchange between kinetic and internal modes. For the present study, the simulations are performed by using a five-species reacting air gas model while considering energy exchange between translational, rotational, and vibrational modes. The molecular gas constants used in the current study are those given in Ref. 9. Also, a rotational relaxation collision number of 5 and a temperature dependent vibrational collision number (Eq. 6.53 of Ref. 9) were used. More details regarding the DS3V code can be found in Ref. 7, and examples of recent validation studies are presented in Ref. 8 .

For all simulations, the surface is assumed to be noncatalytic and at a specified wall temperature. As for gas-surface interactions, they are assumed to be diffuse, with full energy accommodation.

The geometric size of the computational domain was varied with the degree of rarefaction of the freestream flow, since the influence of the body on the external flow at high Knudsen numbers extends outward a greater distance than is the case for a denser flow. The total number of cells in the computational domain was also a variable. The grid adaptation used in the current study nominally used 20 simulated molecules per cell. The total number of molecules used in the simulations ranged from approximately 1 to 16 million.

An indicator of the resolution achieved in a given simulation is given by the ratio of the mean collision separation between collision partners to the local mean free path $(\mathrm{mcs} / \mathrm{mfp})$. For blunt body flows, as considered herein, the average value for this parameter over the computational domain should be much less than 1 to ensure that the values of $m c s / m f p$ are less than 1 adjacent to the surface. If these guidelines are not met, the calculated results will be inaccurate. Results are presented where the failure to meet this criterion and the resulting impact on the calculated forces and moments are demonstrated.

\section{B. Navier-Stokes Analyses}

Navier-Stokes analyses are performed by using the LAURA computational fluid dynamics code. ${ }^{10-12}$ LAURA is an upwind-bias, point-implicit/line-inplicit relaxation algorithm for obtaining the numerical solution to the Navier-Stokes equations for three-dimensional, viscous, hypersonic flows in thermochemical nonequilibrium. LAURA has both the thin layer and full NS options, and both options were exercised in the current study. All of the LAURA simulations assumed the flow to be a reacting gas mixture with the surface boundary conditions consisting of a constant wall temperature, a noncatalytic surface, and no slip or temperature jump. The volume grid consists of 24 blocks with a total of 1966000 cells, and in the direction normal to the wall, there are 80 cells, which cover the region from the wall to the outer boundary. Grid adaption assured cell Reynolds number adjacent to the wall at a nominal value no greater than 0.5 for the highest altitude (95 $\mathrm{km})$ and 5.0 for the lowest altitude $(65 \mathrm{~km})$. The structured surface grid consisted of 24576 cells. To balance the computational load, calculations were performed on 12 dual processor $2.8 \mathrm{GHz}$ Opteron workstations with one block assigned to each of the 24 processors. Solutions were considered converged when the surface properties became steady and changed little after additional integration cycles.

\section{Free Molecular and Newtonian Analyses}

The free molecular (FM) and modified Newtonian (MN) results were obtained with the DACFREE code of R. G. Wilmoth (private communication, July 2005). DACFREE computes aerodynamic forces and moments on arbitrary bodies using standard free molecular and modified Newtonian methods. This code can handle arbitrary geometries specified as an unstructured collection of triangles, and for the present study, the surface grid was the same as that used in the DSMC simulations.

\section{Conditions and Results}

\section{A. Conditions}

Considerable resources were devoted to quantifying the impact of the aerothermodynamic environment on the Apollo Command Module during reentry, particularly the thermal protection system. Table 1, based on the data presented in Ref. 2, list some of the reentry parameters for the 4 unmanned Apollo heat-shieldqualification flight tests, two at orbital entry velocities and two at superorbital entry velocities (Apollo 6 entered at $1.128 \mathrm{~km} / \mathrm{s}$ less than was planned due to a re-ignition failure in the upper stage ${ }^{3}$ ). The current 
study focuses on an altitude range of 200 to $65 \mathrm{~km}$ at $9.6 \mathrm{~km} / \mathrm{s}$ (corresponding to the Apollo 6 reentry condition) at an angle of incidence of -25 degrees, for a range of incidence angles at an altitude of $105 \mathrm{~km}$, and for a range of reentry velocities $(7.68$ to $15 \mathrm{~km} / \mathrm{s})$ at -25 degrees incidence and $105 \mathrm{~km}$ altitude.

The axisymmetric geometry for the Apollo Command Module used in the present study is shown in Fig. 1, which does not account for thermal protection thickness variations between the leeward and windward sides. The Apollo capsule was flown at an angle of incidence while using an offset center of gravity (location used in the current study is listed in Fig. 1). The Apollo capsule has a truncated spherical section, followed by a toroidal section, and then a conical section. As discussed by Bertin ${ }^{19}$ (page 291), the sonic point, which occurs near the tangency point of the spherical heat shield and the toroidal surface, are inboard of the locations that they would occupy for a full spherical cap. As a result, the entire flowfield in the subsonic portion of the shock layer is modified with respect to those for a full spherical cap.

When the pressures and shear stresses are integrated over the surface, the resultant force acts at the center-of-pressure (cp) of the capsule. The total force vector is usually resolved into components, as shown in Fig. 2. Nomenclature used for the body (axial and normal) and velocity (drag and lift) oriented coordinates are as shown in Fig. 2.

For the DSMC simulations, an unstructured surface grid (Figs. 3 and 4) is used to define the body surface, where the number of surface points and triangles were 1912 and 3718 , respectively. This surface resolution was deemed adequate after a calculation was made for a case (105 km altitude and -25 degrees incidence) with a much finer surface grid resoultion (5946 and 11,178 points and triangles, respectively) and with a negligible change in results. Note that the numerical simulations take advantage of the problem symmetry in that the flow is computed about only half of the capsule.

Free-stream atmospheric conditions are listed in Tables 2 and 3 and are based on the data of Jacchia ${ }^{20}$ (an exospheric temperature of $1200 \mathrm{~K}$ ) for altitudes of $90 \mathrm{~km}$ and above and on that of Ref. 21 for altitudes less than $90 \mathrm{~km}$. The surface temperatures are assumed to be uniformly distributed at the values listed in Tables 4, 6, and 8, and are calculated based on the minimum value resulting from either the free-molecular radiative equilibrium heat transfer to the stagnation point or the radiative equilibrium temperature based on the stagnation point heating from the correlation of Sutton (Eq. 1 of Ref. 22). The free-stream Knudsen numbers listed in Table 3 are based on the free-stream number density, a characteristic length of $3.912 \mathrm{~m}$ (maximum capsule diameter), and a constant molecular diameter of $3.78 \times 10^{-10} \mathrm{~m}$.

\section{B. Rarefaction and Grid Resolution Effects}

Results of the numerical simulations are presented in Tables 4 through 8 and Figs. 5 through 11 . Table 4 and Figs. 5 through 7 present results that show the effects of rarefaction, as expresed by the Knudsen number, on the aerodynamic and moment coefficients and the location of the center of pressure. The lift $\left(\mathrm{C}_{L}\right)$ and lift-todrag (L/D) coefficients are shown to be extremely sensitive to rarefaction, increasing in value with decreasing rarefaction. All results presented in Fig. 5 were obtained with the DS3V code, and as noted in this figure these results have been generated with a simulation merit parameter that is too large for the lower altitude cases: that is, the value of $m c s / m f p$ is of order one or larger. Table 7 provides data that is useful in assessing the goodness of the simulation for 5 different altitudes between 105 and $85 \mathrm{~km}$. These grid sensitivity studies were made by sequentially increasing the number of simulated molecules and adapting the grid to 20 molecules per cell. For the 105 and $100 \mathrm{~km}$ conditions, we see negligible to small changes in the coefficients as the resolution is refined; that is, by increasing the number of simulated molecules and computational cells with a corresponding reduction in the magnitude of the solution merit parameter $\mathrm{mcs} / \mathrm{mfp}$. However, for the 95 to $85 \mathrm{~km}$ conditions, it is not possible with a single-processor personal computer to achieve an adequate grid resolution. To determine the impact of the lack of grid resolved DS3V simulations for the lower altitude conditions, Navier-Stokes solutions were generated for these conditions and lower altitudes, as presented in Table 8. When a comparison of the DS3V and LAURA results at $85 \mathrm{~km}$ (Tables 4 and 8 ) is made, one is able to see the quantitative impact of a poorly resolved simulation and its impact of the predicted aerodynamics. For example, the ratio of DS3V to LAURA results at $85 \mathrm{~km}$ for drag, lift, and L/D coefficients are 1.06, 0.89, and 0.84 , respectively, in which the DS3V simulation was made with a global mean mcs $/ \mathrm{mfp}$ of 2.45 . Recall that a grid resolved DS3V simulation requires a mcs $/ \mathrm{mfp}$ value that is of order 0.1 , clearly demonstrated in the results shown in Table 7 .

Aerodynamic data presented if Figs. 6 and 7 includes both the NS and the grid resolved DSMC results, and provides coverage in terms of hard sphere free-stream Knudsen numbers of approximately six orders of magnitude. Even though an overlap with the two simulation methods has not been demonstrated, the results 
clearly show that two very different numerical methods are producing similar and reasonably consistent results (joined by dash lines) in the 95 to $100 \mathrm{~km}$ altitude range (Kn number of approximately 0.024). As detailed in Table 8, the NS results includes two modeling assumptions accounting for different gas models (a 5 -species model that does not account for ionization and 7- and 11-species models that account for ionized species) and the actual equations solved (full NS [FNS] or thin layer NS [TLNS]). Results for the $85 \mathrm{~km}$ flow conditions show little sensitivity of the aerodynamics to the effects of either TLNS versus FNS or whether the effects of ionization are included. Results presented in Ref. 23 indicated that as the flow becomes more rarefied, the full NS provides better agreement with the DSMC results and the agreement persists to more rarefied conditions.

Figure 7 details the movement of the center of pressure and the corresponding moment coefficient about the center of gravity as a function of Knudsen number. As the capsule descends from 200 to $65 \mathrm{~km}$, the center of pressure experiences a substantial translation as it moves from a position forward of the center of gravity to one well aft. The corresponding change in the moment coefficient (Fig. 7) is from a negative value to a small positive value.

\section{Effects of Angle of Incidence}

Figures 8 though 10 and Table 5 present data that show the dependence of the Apollo capsule aerodynamics to variations in angle of incidence for the $105 \mathrm{~km}$ altitude conditions and $9.6 \mathrm{~km} / \mathrm{s}$. Figure 8 highlights the dependence of $\mathrm{L} / \mathrm{D}$ on incidence angle and also demonstrates its sensitivity to rarefaction by including the free molecular (FM) and modified Newtonian (MN) results. The FM and MN results were generated with the DACFREE code at the $200 \mathrm{~km}$ and $85 \mathrm{~km}$ conditions, respectively.

Results of the DSMC simulations for the force coefficients are presented in Fig. 9 as a function of incidence. Results for the center of pressure location and the moment coefficient about the offset center of gravity are presented in Fig. 10. These simulations show that the stable trim point for the Apollo capsule at $105 \mathrm{~km}$ altitude occurs at an incidence angle of -164 degrees rather than the nominal -25 degrees flown by Apollo 6; that is, the capsule is statically unstable for much, if not all, of the transitional flow regime, a result not that uncommon ${ }^{16,17}$ for capsules in the transitional rarefied regime.

\section{Effects of Free-Stream Velocity}

To examine the effects of free-stream velocity variations, simulations were made for the Apollo capsule at an altitude of $105 \mathrm{~km}$ and -25 degrees incidence for 5 free-stream velocities ranging from 7.7 to $15 \mathrm{~km} / \mathrm{s}$ (Table 6). Four of the velocities correspond to the nominal re-entry conditions of the 4 unmanned Apollo qualification flight tests (Table 1). The $15 \mathrm{~km} / \mathrm{s}$ velocity is representative of the upper bounds for a Mars return mission. Consequently, this range of entry velocities is inclusive of that for reentry from LEO, lunar return, and Mars return missions. Results of the simulations for variations in free-stream velocity show (Table 6 and Fig. 11) that the changes in the aerodynamic coefficients with increasing velocity are similar to those incurred with increasing rarefaction; that is, the magnitude of the drag, axial, and normal force coefficients increases with increasing free-stream velocity while the magnitude of the lift and lift-to-drag ratio coefficients decrease with increasing velocity. These findings are consistent with the correltaions demonstrated by Wilhite et al. ${ }^{18}$ (Fig. $7, \mathrm{p}$ 172) for the Shuttle Orbiter axial-force coefficients as a function of a viscous correlation parameter.

\section{Concluding Remarks}

A computational study of hypersonic flow over the Apollo Command Module is made by using the direct simulation Monte Carlo (DSMC) method. The computations are made for Earth entry conditions, similar to that experienced by Apollo 6, by using a 5-species reacting air model. Simulations are made for altitudes of 200 to $85 \mathrm{~km}$, free-stream velocities of 7.7 to $15 \mathrm{~km} / \mathrm{s}$, and various angles of incidence. Results of the simulations show the effect of both rarefaction and entry velocities on the aerodynamic forces and moments. Also, results are presented that show the sensitivity of solutions to grid resolution and the approximate bounds of reliable results when using the DSMC code called DS3V.

The rarefied results are anchored in the continuum regime with simulations made with a Navier-Stokes code for altitudes of 95 to $65 \mathrm{~km}$ and a free-stream velocity of $9.6 \mathrm{~km} / \mathrm{s}$. Included in the Navier-Stokes simulations were sensitivity studies regarding the use of full Navier Stokes or thin layer Navier Stokes and the impact of including or not including the effects of ionization on the calculated aerodynamics. 
Significant findings of the present investigation are as follows: (1) the lift and lift-to-drag coefficients increase substantially with decreasing rarefaction, (2) the location of the longitudinal center of pressure is very sensitive to the degree of rarefaction, (3) the Apollo Command Module is statically unstable for much of the rarefied flow regime, (3) changes in the aerodynamic coefficients with increasing velocity have the same trend as that for increasing rarefaction, (4) the present DSMC simulations are shown to be reliable based on grid resolution studies for altitudes from free molecular to approximately $100 \mathrm{~km}$ altitude, (5) even though an overlap of grid converged DSMC and NS simulations were not realized in the current study, the two simulation techniques were sufficiently close in altitude space to indicate that the two simulation methods provide consistent results as they approach each other in the 95 to $100 \mathrm{~km}$ altitude interval, and (6) that the NS results for aerodynamics demonstrate a very small sensitivity to the 3 gas model used $(5,7$, and 11 species models) for the $85 \mathrm{~km}$ altitude conditions.

\section{Acknowledgments}

The author acknowledges the assistance of the following individuals: Victor Lessard of Genex Systems for providing the unstructured surface grid and Richard Wheless of NCI Information Systems for assisting with the graphics.

\section{References}

${ }^{1}$ Sietzen, F., "From Mercury to CEV: Space Capsules Reemerge," Aerospace America, February 2005, pp.26-33.

${ }^{2}$ Lee, D. B., "Apollo Experience Report-Aerothermodynamics Evaluation," NASA TN D-6843, June 1972.

${ }^{3}$ Lee, D. B. and Goodrich, W. D., "The Aerothermodynamic Environment of the Apollo Command Module During Superorbital Entry," NASA TN D-6792, April 1972.

${ }^{4}$ Lee, D. B., Bertin, J. J., and Goodrich, W. D., "Heat-Transfer Rate and Pressure Measurements Obtained During Apollo Orbital Entries," NASA TN D-6028, April 1970.

${ }^{5}$ Eillje, E. R., "Entry Flight Aerodynamics from Apollo Mission AS-202," NASA TN D-4185, October 1967.

${ }^{6}$ Anon, "Aerodynamic Data Manual for Project Apollo (North American Aviation, Inc.)", NASA-CR-82907, October 1965.

${ }^{7}$ Bird, G. A., Visual DSMC Program for Three-Dimensional Flows. The DS3V Program User's Guide, Version 1.2, March 2005.

${ }^{8}$ Bird, G. A., "The DS2V/3V Program Suite for DSMC Calculations," Rarefied Gas Dynamics, 24th International Symposium on Rarefied Gas Dynamics, edited by M. Capitelli, American Institute of Physics, Vol. 762, New York, 2005, pp.541-546.

${ }^{9}$ Bird, G. A., Molecular Gas Dynamics and the Direct Simulation of Gas Flows. Oxford: Clarendon Press, 1994.

${ }^{10}$ Gnoffo, P. A., "An Upwind-Biased, Point-Implicit Algorithm for Viscous, Compressible Perfect-Gas Flows," NASA TP2953, Feb. 1990.

${ }^{11}$ Gnoffo, P. A., Gupta, R. N., and Shinn, J. L, "Equations and Physical Models for Hypersonic Air Flows in Thermal and Chemical Nonequilibrium," NASA TP-2867, Feb. 1989

${ }^{12}$ Cheatwood, F. M., and Gnoffo, P. A., "User's Manual for the Langley Aerothermodynamic Upwind Relaxation Algorithm (LAURA)," NASA TM 4674, April 1996.

${ }^{13}$ Borgnakke, C., and Larsen, P. S., "Statistical Collision Model for Monte Carlo Simulation of Polyatomic Gas Mixture," Journal of Computational Physics, Vol. 18, No. 4, 1975, pp. 405-420.

${ }^{14}$ Padilla, J. F., Tseng, K.-C. and Boyd, I. D., "Analysis of Entry Vehicle Aerothermodynamics Using the Direct Simulation Monte Carlo Method," AIAA Paper 2005-4681, June 2005.

${ }^{15}$ Vashchenkov, P., Kashkovsky, A. Ivanov, M., "Numerical Analysis of High Altitude Aerodynamics of Reentry Vehicles," AIAA Paper 2005-3409, May 2005.

${ }^{16}$ Wilmoth, R. G., Mitcheltree, R. A., and Moss, J. N., "Low-Density Aerothermodynamics of the Stardust Sample Return Capsule," Journal of Spacecraft and Rockets, Vol. 36, No.3, 1999, pp. 436-441.

${ }^{17}$ Moss, J. N., Blanchard, R. C., Wilmoth, R. G., and Braun, R. D., "Mars Pathfinder Rarefied Aerodynamics: Computations and Measurements," Journal of Spacecraft and Rockets, Vol. 36, No.3, 1999, pp. 330-339.

${ }^{18}$ Wilhite, A. W., Arrington, J. P., and McCandless, R. S., "Performance Aerodynamics of Aeroassisted Orbital Transfer Vehicles," Progress in Astronautics and Aeronautics, Vol. 96, Thermal Design of Aeroassisted Orbital Transfer Vehicles, edited by H.F. Nelson, AIAA, New York, 1985, pp. 165-185.

${ }^{19}$ Bertin, J. J., Hypersonic Aerothermodynamics, AIAA Education Series, Washington, DC, 1994 Superorbital Entry," NASA TN D-6792, April 1972.

${ }^{20}$ Jacchia, L. G., "Thermospheric Temperature, Density, and Composition: New Models," Smithsonian Astrophysical Observatory, Cambridge, MA, Special Rept. 375, March 1977.

${ }^{21}$ Anon, "U. S. Standard Atmosphere, 1962," Dec. 1962.

${ }^{22}$ Sutton, K., "Air Radiation Revisited," AIAA Paper 84-1733, June 1984.

${ }^{23}$ Moss, J. N., Glass, C. G., Hollis, B. R., and Van Norman, J. W., "Low-Density Aerothermodynamics of the Inflatable Re-entry Vehicle Experiment (IRVE)," AIAA Paper 2006-1189, Jan. 2006. 
Table 1. Reentry conditions for the Apollo Command Module flight tests.

\begin{tabular}{cccccc}
\hline \hline Flight Designation & $V_{\infty}, \mathrm{m} / \mathrm{s}$ & $\alpha, \mathrm{deg}$ & $\gamma, \mathrm{deg}$ & Max Decel, g's & Theoretical Max Heating, W/ $\mathrm{cm}^{2}$ \\
\hline AS-201 & 7.67 & -20 & -8.6 & 14.3 & 186 \\
AS-202 & 8.29 & -18 & -3.5 & 2.4 & 91 \\
Apollo 4 & 10.73 & -25 & -6.9 & 7.3 & 488 \\
Apollo 6 & 9.6 & -25 & -5.9 & 4.6 & 237 \\
\hline \hline
\end{tabular}

Table 2. Free-stream conditions.

\begin{tabular}{ccccc}
\hline \hline Altitude, $\mathrm{km}$ & $n_{\infty}, \mathrm{m}^{-3}$ & $\rho_{\infty}, \mathrm{kg} / \mathrm{m}^{3}$ & $T_{\infty}, \mathrm{K}$ & Molecular weight \\
\hline 200 & $8.9996 \times 10^{15}$ & $3.2829 \times 10^{-10}$ & 1026 & 21.970 \\
170 & $2.2702 \times 10^{16}$ & $8.7777 \times 10^{-10}$ & 892 & 23.290 \\
150 & $5.3055 \times 10^{16}$ & $2.1383 \times 10^{-9}$ & 733 & 24.273 \\
140 & $9.3528 \times 10^{16}$ & $3.8548 \times 10^{-9}$ & 625 & 24.823 \\
135 & $1.3149 \times 10^{17}$ & $5.4862 \times 10^{-9}$ & 564 & 25.127 \\
130 & $1.9429 \times 10^{17}$ & $8.2075 \times 10^{-9}$ & 500 & 25.441 \\
125 & $3.0598 \times 10^{17}$ & $1.3100 \times 10^{-8}$ & 433 & 25.783 \\
120 & $5.2128 \times 10^{17}$ & $2.2642 \times 10^{-8}$ & 368 & 26.159 \\
115 & $9.8562 \times 10^{17}$ & $4.3575 \times 10^{-8}$ & 304 & 26.626 \\
110 & $2.1246 \times 10^{18}$ & $9.6068 \times 10^{-8}$ & 247 & 27.232 \\
105 & $5.0947 \times 10^{18}$ & $2.3640 \times 10^{-7}$ & 208 & 27.943 \\
100 & $1.1898 \times 10^{19}$ & $5.5824 \times 10^{-7}$ & 194 & 28.258 \\
95 & $3.1167 \times 10^{19}$ & $1.4835 \times 10^{-6}$ & 189 & 28.613 \\
90 & $7.0755 \times 10^{19}$ & $3.3848 \times 10^{-6}$ & 188 & 28.810 \\
85 & $1.6540 \times 10^{20}$ & $7.9550 \times 10^{-6}$ & 181 & 28.960 \\
75 & $9.0130 \times 10^{20}$ & $4.3350 \times 10^{-5}$ & 200 & 28.960 \\
65 & $3.4651 \times 10^{21}$ & $1.6665 \times 10^{-4}$ & 293 & 28.960 \\
\hline \hline
\end{tabular}


Table 3. Atmospheric composition and Knudsen numbers for reentry conditions.

\begin{tabular}{crccc}
\hline \hline Altitude, $\mathrm{km}$ & $\mathrm{X}_{O 2}$ & $\mathrm{X}_{N 2}$ & $\mathrm{X}_{O}$ & $\mathrm{Kn}_{\infty, D, H S}$ \\
\hline 200 & 0.03146 & 0.45476 & 0.51378 & 44.74 \\
170 & 0.04354 & 0.54820 & 0.40826 & 17.74 \\
150 & 0.05461 & 0.61557 & 0.32982 & 7.59 \\
140 & 0.06181 & 0.65173 & 0.28646 & 4.31 \\
135 & 0.06593 & 0.67158 & 0.26248 & 3.06 \\
130 & 0.07089 & 0.69113 & 0.23799 & 2.07 \\
125 & 0.07679 & 0.71171 & 0.21150 & 1.32 \\
120 & 0.08451 & 0.73271 & 0.18278 & 0.773 \\
115 & 0.09779 & 0.75386 & 0.14835 & 0.408 \\
110 & 0.12323 & 0.77042 & 0.10635 & 0.190 \\
105 & 0.15808 & 0.78319 & 0.05873 & 0.081 \\
100 & 0.17683 & 0.78440 & 0.03877 & 0.0338 \\
95 & 0.20040 & 0.78687 & 0.01273 & 0.0139 \\
90 & 0.20905 & 0.78748 & 0.00347 & 0.0057 \\
85 & 0.23720 & 0.76280 & 0.00000 & 0.0024 \\
75 & 0.23720 & 0.76280 & 0.00000 & 0.00045 \\
65 & 0.23720 & 0.76280 & 0.00000 & 0.00012 \\
\hline \hline
\end{tabular}

Table 4. Effect of rarefaction on aerodynamics for $-25^{\circ}$ incidence and a free-stream velocity of $9.6 \mathrm{~km} / \mathrm{s}$.

\begin{tabular}{cccccccc}
\hline \hline Alt., km & $T_{W}, \mathrm{~K}$ & $C_{A}$ & $C_{N}$ & $C_{m, 0}$ & $C_{D}$ & $C_{L}$ & $L / D$ \\
\hline 200 & 234 & 1.731 & -0.777 & 0.113 & 1.898 & 0.027 & 0.014 \\
170 & 300 & 1.734 & -0.775 & 0.112 & 1.899 & 0.030 & 0.016 \\
150 & 373 & 1.723 & -0.757 & 0.113 & 1.881 & 0.042 & 0.022 \\
140 & 434 & 1.702 & -0.728 & 0.112 & 1.851 & 0.060 & 0.032 \\
135 & 474 & 1.698 & -0.706 & 0.112 & 1.838 & 0.078 & 0.042 \\
130 & 524 & 1.679 & -0.685 & 0.111 & 1.812 & 0.089 & 0.049 \\
125 & 589 & 1.664 & -0.655 & 0.110 & 1.785 & 0.110 & 0.062 \\
120 & 675 & 1.658 & -0.620 & 0.110 & 1.764 & 0.139 & 0.079 \\
115 & 795 & 1.644 & -0.566 & 0.110 & 1.729 & 0.181 & 0.105 \\
110 & 920 & 1.604 & -0.477 & 0.112 & 1.655 & 0.245 & 0.148 \\
105 & 1029 & 1.529 & -0.374 & 0.113 & 1.544 & 0.307 & 0.199 \\
100 & 1146 & 1.448 & -0.279 & 0.109 & 1.431 & 0.359 & 0.251 \\
95 & 1295 & 1.380 & -0.226 & 0.104 & 1.346 & 0.379 & 0.281 \\
90 & 1436 & 1.354 & -0.211 & 0.100 & 1.316 & 0.381 & 0.290 \\
85 & 1598 & 1.351 & -0.205 & 0.099 & 1.311 & 0.385 & 0.293 \\
\hline \hline
\end{tabular}


Table 5. Effect of incidence angle on aerodynamics for a free-stream velocity of $9.6 \mathrm{~km} / \mathrm{s}$, an altitude of $105 \mathrm{~km}$, and a wall temperature of $1029 \mathrm{~K}$.

\begin{tabular}{ccccccccc}
\hline \hline$\alpha, \mathrm{deg}$ & $C_{A}$ & $C_{N}$ & $C_{m, 0}$ & $C_{D}$ & $C_{L}$ & $L / D$ & $C_{m, c g}$ & $C_{m, c g}^{*}$ \\
\hline 0 & 1.775 & 0.000 & 0.000 & 1.775 & 0.000 & 0.000 & -0.0726 & -0.0726 \\
2 & 1.773 & 0.031 & -0.010 & 1.773 & 0.031 & 0.017 & -0.0732 & -0.0719 \\
5 & 1.764 & 0.078 & -0.024 & 1.764 & -0.077 & -0.043 & -0.0735 & -0.0708 \\
10 & 1.734 & 0.154 & -0.048 & 1.734 & -0.149 & -0.086 & -0.0734 & -0.0684 \\
15 & 1.683 & 0.229 & -0.071 & 1.685 & -0.214 & -0.127 & -0.0723 & -0.0654 \\
20 & 1.615 & 0.304 & -0.093 & 1.621 & -0.267 & -0.165 & -0.0697 & -0.0624 \\
25 & 1.529 & 0.374 & -0.113 & 1.544 & -0.307 & -0.199 & -0.0659 & -0.0592 \\
30 & 1.428 & 0.445 & -0.132 & 1.460 & -0.328 & -0.225 & -0.0601 & -0.0568 \\
35 & 1.317 & 0.506 & -0.152 & 1.370 & -0.341 & -0.249 & -0.0571 & -0.0507 \\
40 & 1.199 & 0.571 & -0.171 & 1.285 & -0.334 & -0.260 & -0.0534 & -0.0447 \\
45 & 1.077 & 0.639 & -0.194 & 1.213 & -0.309 & -0.255 & -0.0534 & -0.0374 \\
60 & 0.678 & 0.842 & -0.258 & 1.069 & -0.166 & -0.156 & -0.0390 & -0.0165 \\
75 & 0.253 & 0.986 & -0.295 & 1.018 & 0.011 & 0.011 & -0.0166 & -0.0041 \\
90 & -0.143 & 1.047 & -0.298 & 1.047 & 0.143 & 0.136 & 0.0147 & -0.0030 \\
95 & -0.258 & 1.052 & -0.292 & 1.071 & 0.166 & 0.155 & 0.0266 & -0.0054 \\
105 & -0.460 & 1.051 & -0.275 & 1.134 & 0.172 & 0.152 & 0.0514 & -0.0137 \\
120 & -0.708 & 1.018 & -0.241 & 1.235 & 0.104 & 0.084 & 0.0861 & -0.0282 \\
135 & -0.915 & 0.918 & -0.192 & 1.296 & -0.002 & -0.001 & 0.1143 & -0.0394 \\
150 & -1.129 & 0.736 & -0.133 & 1.346 & -0.073 & -0.054 & 0.1285 & -0.0362 \\
155 & -1.207 & 0.649 & -0.114 & 1.368 & -0.079 & -0.057 & 0.1253 & -0.0266 \\
160 & -1.279 & 0.545 & -0.094 & 1.388 & -0.074 & -0.054 & 0.1180 & -0.0134 \\
165 & -1.341 & 0.424 & -0.072 & 1.406 & -0.063 & -0.045 & 0.1074 & 0.0023 \\
170 & -1.389 & 0.290 & -0.049 & 1.419 & -0.045 & -0.032 & 0.0930 & 0.0206 \\
175 & -1.418 & 0.147 & -0.025 & 1.425 & -0.023 & -0.016 & 0.0766 & 0.0394 \\
178 & -1.427 & 0.059 & -0.010 & 1.428 & -0.010 & -0.007 & 0.0661 & 0.0506 \\
180 & -1.429 & 0.000 & -0.000 & 1.429 & -0.000 & -0.000 & 0.0584 & 0.0584 \\
\hline \hline
\end{tabular}

${ }^{*}$ The moment coefficient for the corresponding negative angle of incidence.

Table 6. Effect of velocity on aerodynamics for a $-25^{\circ}$ incidence angle and an altitude of $105 \mathrm{~km}$.

\begin{tabular}{cccccccc}
\hline \hline$V_{\infty}, \mathrm{km} / \mathrm{s}$ & $T_{W}, \mathrm{~K}$ & $C_{A}$ & $C_{N}$ & $C_{m, 0}$ & $C_{D}$ & $C_{L}$ & $L / D$ \\
\hline 7680 & 871 & 1.515 & -0.361 & 0.113 & 1.526 & 0.313 & 0.205 \\
8290 & 922 & 1.520 & -0.365 & 0.113 & 1.532 & 0.312 & 0.204 \\
9600 & 1029 & 1.529 & -0.374 & 0.113 & 1.544 & 0.307 & 0.199 \\
10759 & 1121 & 1.535 & -0.383 & 0.113 & 1.553 & 0.302 & 0.194 \\
15000 & 1439 & 1.552 & -0.410 & 0.113 & 1.579 & 0.284 & 0.180 \\
\hline \hline
\end{tabular}


Table 7. Sensitivity of aerodynamic forces and moments to simulation merit parameter ( $\mathrm{mcs} / \mathrm{mfp})$ for a $\mathbf{- 2 5 ^ { \circ }}$ incidence angle and $V_{\infty}=9.6 \mathrm{~km} / \mathrm{s}$.

\begin{tabular}{ccccccccc}
\hline \hline \multirow{2}{*}{ Alt., km } & Mean mcs/mfp & Simulated Molecules & $C_{A}$ & $C_{N}$ & $C_{m, 0}$ & $C_{D}$ & $C_{L}$ & $L / D$ \\
\hline \multirow{2}{*}{105} & 0.130 & $0.951 \times 10^{6}$ & 1.529 & -0.374 & 0.113 & 1.544 & 0.307 & 0.199 \\
& 0.072 & $3.792 \times 10^{6}$ & 1.525 & -0.366 & 0.112 & 1.537 & 0.312 & 0.203 \\
& 0.048 & $9.475 \times 10^{6}$ & 1.522 & -0.363 & 0.112 & 1.533 & 0.315 & 0.205 \\
\hline \multirow{2}{*}{100} & 0.278 & $1.232 \times 10^{6}$ & 1.453 & -0.297 & 0.110 & 1.442 & 0.345 & 0.239 \\
& 0.149 & $4.877 \times 10^{6}$ & 1.448 & -0.284 & 0.110 & 1.432 & 0.354 & 0.247 \\
& 0.103 & $14.536 \times 10^{6}$ & 1.448 & -0.279 & 0.109 & 1.431 & 0.359 & 0.251 \\
\hline \multirow{3}{*}{95} & 0.835 & $1.372 \times 10^{6}$ & 1.404 & -0.263 & 0.107 & 1.384 & 0.355 & 0.256 \\
& 0.462 & $5.429 \times 10^{6}$ & 1.388 & -0.240 & 0.105 & 1.359 & 0.369 & 0.272 \\
& 0.338 & $10.804 \times 10^{6}$ & 1.383 & -0.230 & 0.104 & 1.351 & 0.376 & 0.278 \\
& 0.299 & $16.114 \times 10^{6}$ & 1.380 & -0.226 & 0.104 & 1.346 & 0.379 & 0.281 \\
\hline \multirow{2}{*}{90} & 1.610 & $2.468 \times 10^{6}$ & 1.381 & -0.239 & 0.103 & 1.353 & 0.367 & 0.272 \\
& 0.930 & $9.833 \times 10^{6}$ & 1.354 & -0.211 & 0.100 & 1.316 & 0.381 & 0.290 \\
\hline \hline
\end{tabular}

Table 8. Aerodynamics obtained with the LAURA Navier-Stokes code for $\mathbf{- 2 5}{ }^{\circ}$ incidence angle and 9.6 km/s (results for both full Navier Stokes (FNS) and thin layer Navier Stokes (TLNS)).

\begin{tabular}{ccccccccc}
\hline \hline Alt., km & Models & $T_{W}$ & $C_{A}$ & $C_{N}$ & $C_{m, 0}$ & $C_{D}$ & $C_{L}$ & $L / D$ \\
\hline 95 & FNS, 11 species & 1285 & 1.369 & -0.197 & 0.105 & 1.324 & 0.400 & 0.302 \\
90 & TLNS, 11 species & 1436 & 1.337 & -0.157 & 0.098 & 1.277 & 0.423 & 0.331 \\
85 & FNS, 11 species & 1598 & 1.302 & -0.130 & 0.092 & 1.235 & 0.432 & 0.350 \\
85 & TLNS, 11 species & 1598 & 1.302 & -0.129 & 0.092 & 1.237 & 0.434 & 0.351 \\
85 & TLNS, 7 species & 1598 & 1.306 & -0.129 & 0.091 & 1.233 & 0.433 & 0.351 \\
85 & TLNS, 5 species & 1598 & 1.298 & -0.128 & 0.091 & 1.232 & 0.433 & 0.351 \\
75 & TLNS, 5 species & 1975 & 1.292 & -0.110 & 0.090 & 1.218 & 0.446 & 0.366 \\
65 & TLNS, 5 species & 2337 & 1.295 & -0.104 & 0.088 & 1.217 & 0.453 & 0.372 \\
\hline \hline
\end{tabular}




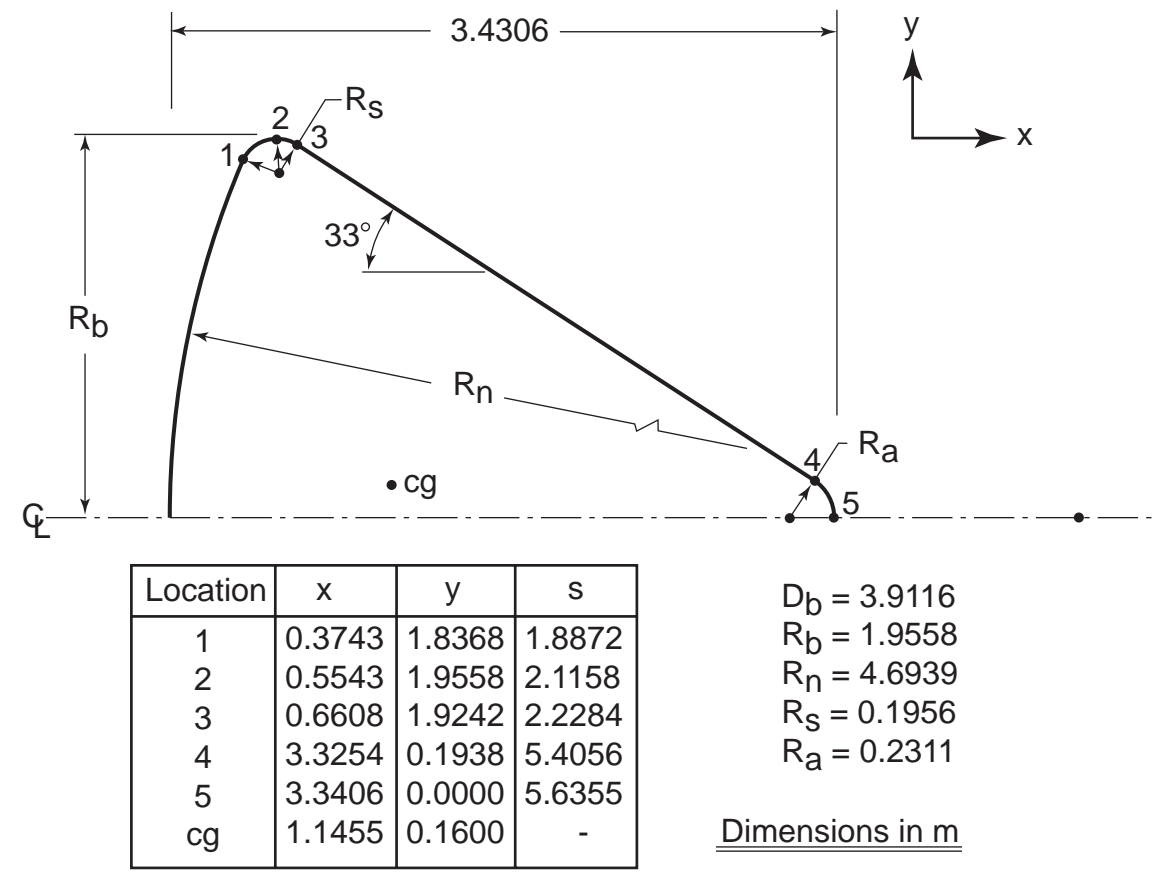

Figure 1. Outer mold line of the Apollo Command Module used in the present work.

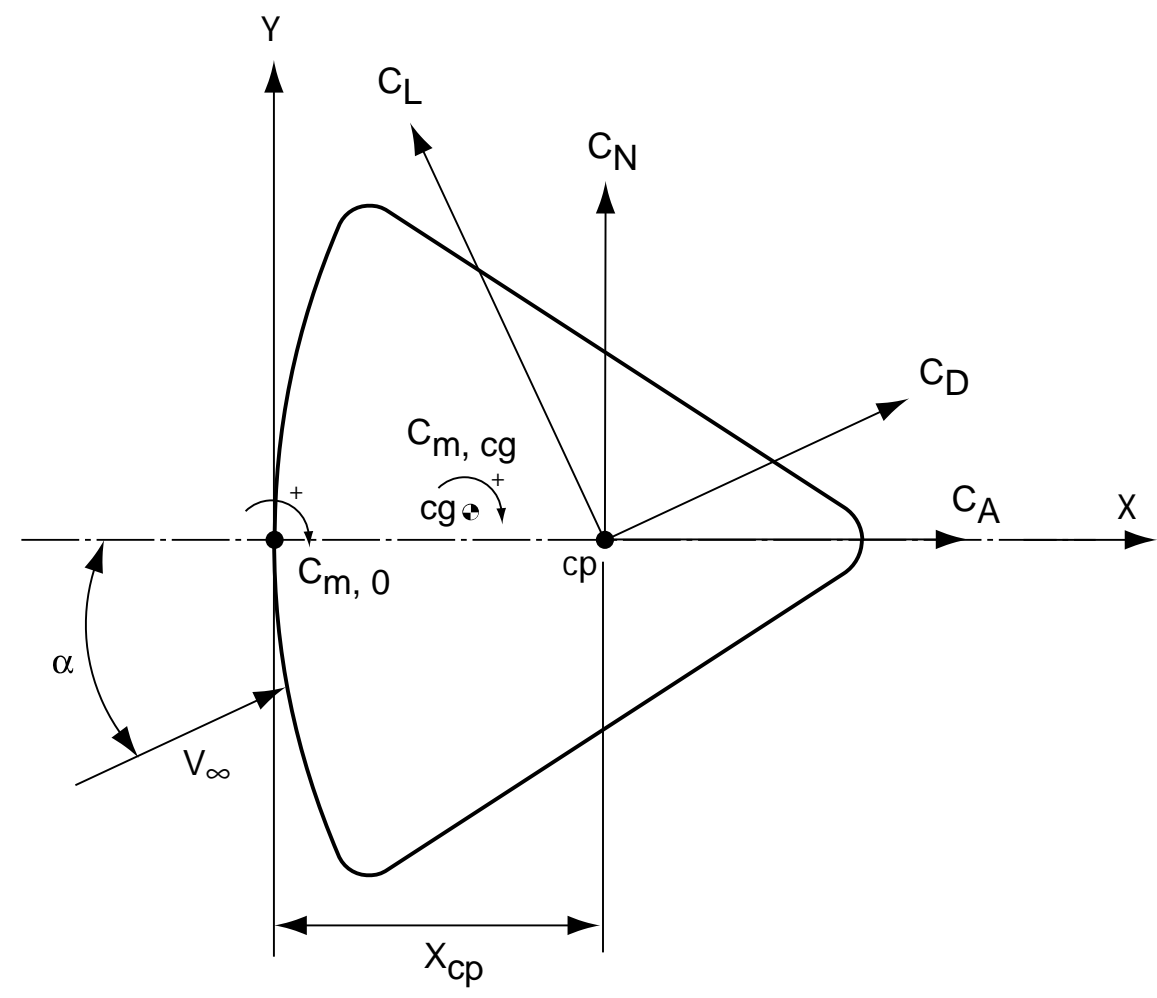

Figure 2. Nomenclature for aerodynamic forces in the pitch plane. 


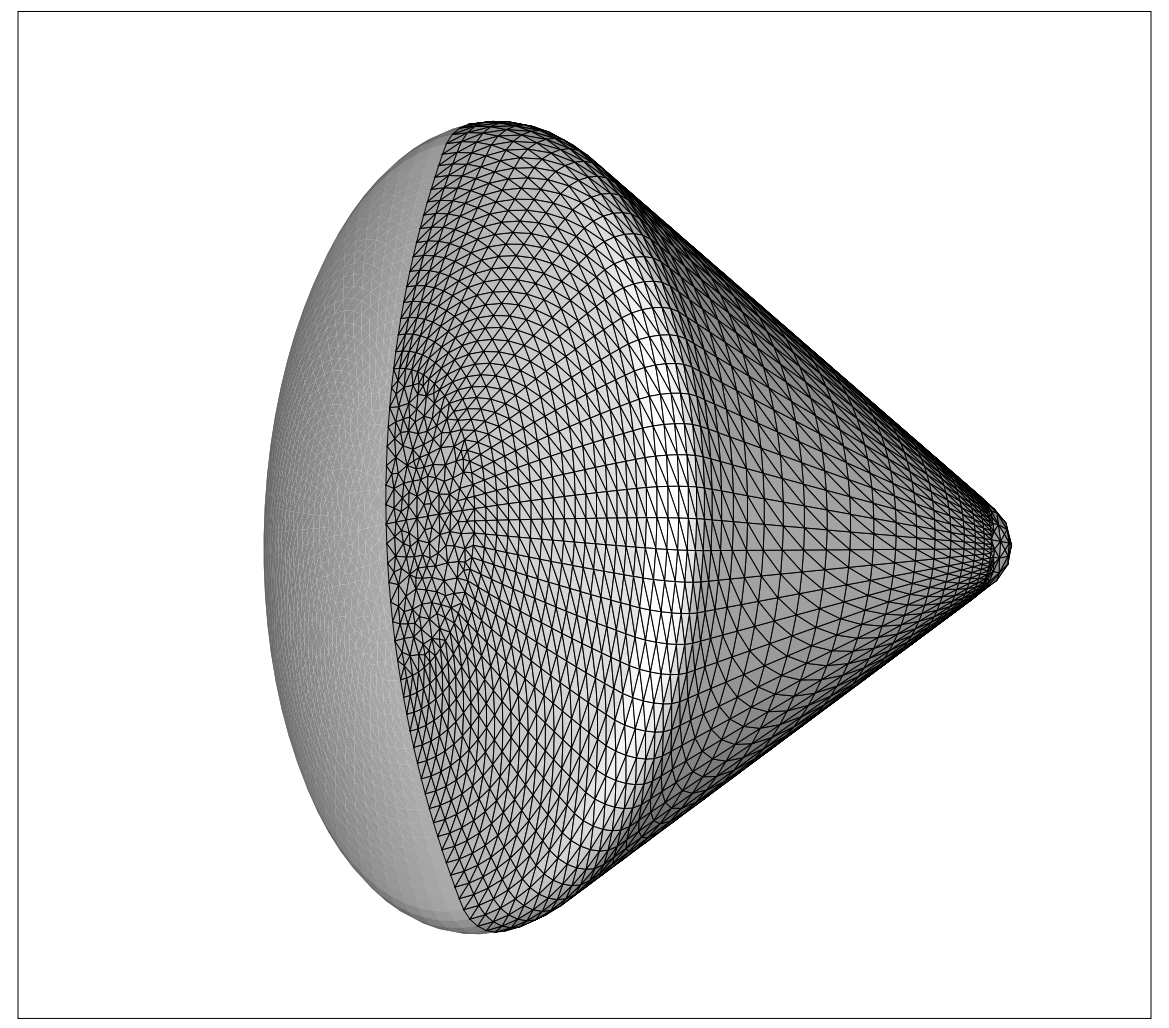

Figure 3. Frontal view of Apollo Command Module unstructured body grid used in present DSMC simulations.

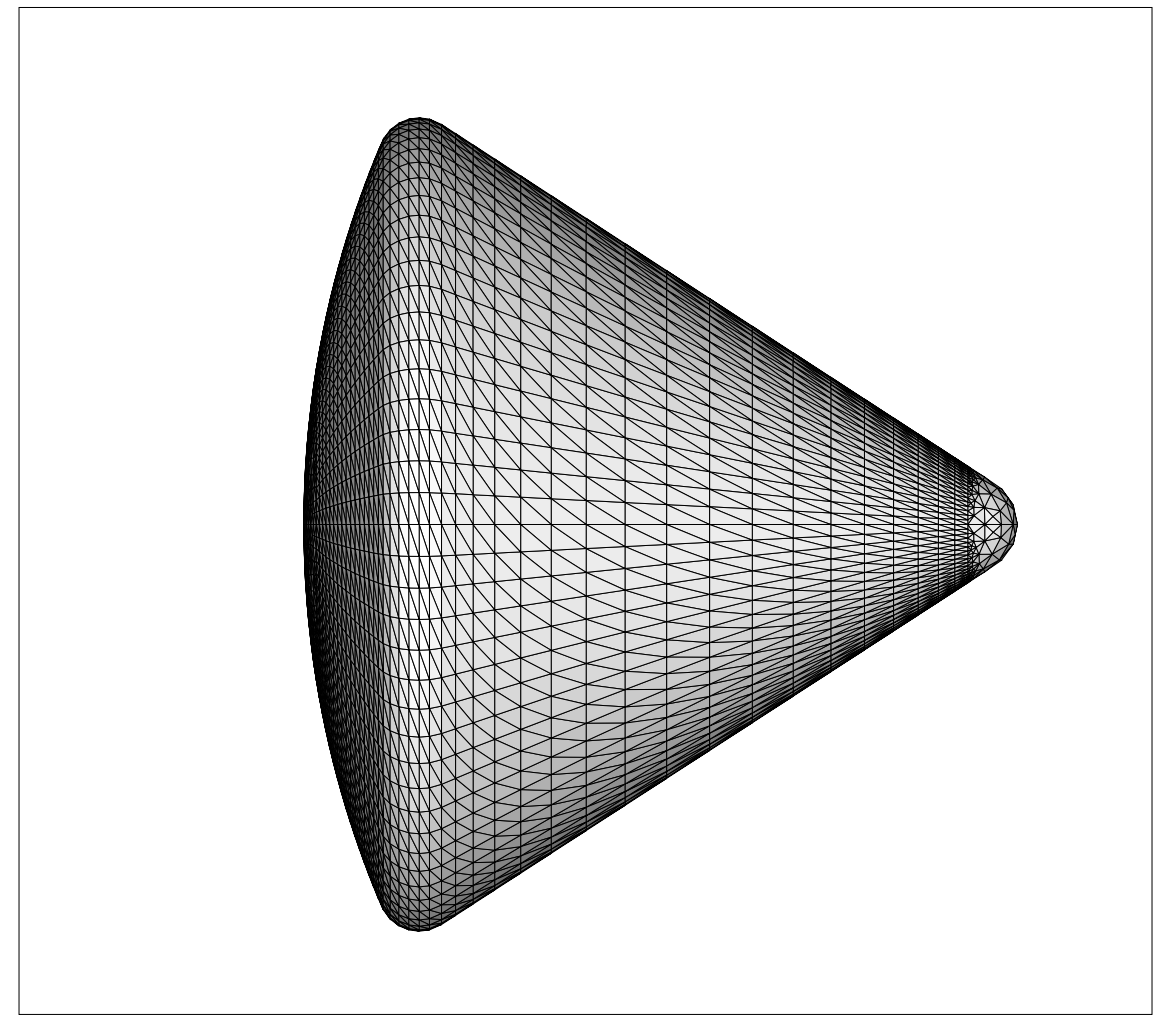

Figure 4. Side view of Apollo Command Module unstructured body grid used in present DSMC simulations. 


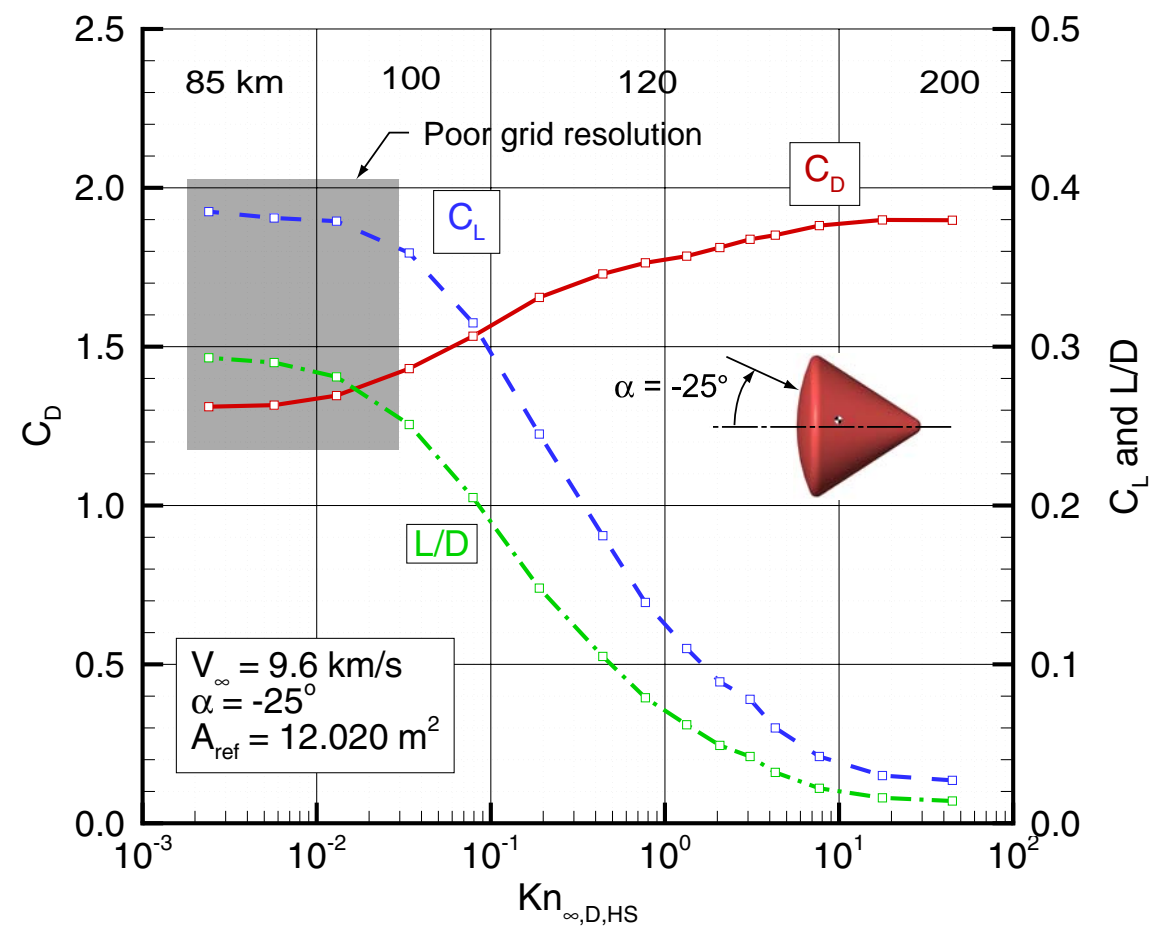

Figure 5. DS3V results for Apollo aerodynamics as a function of rarefaction, including poorly grid resolved results for lower altitudes. 


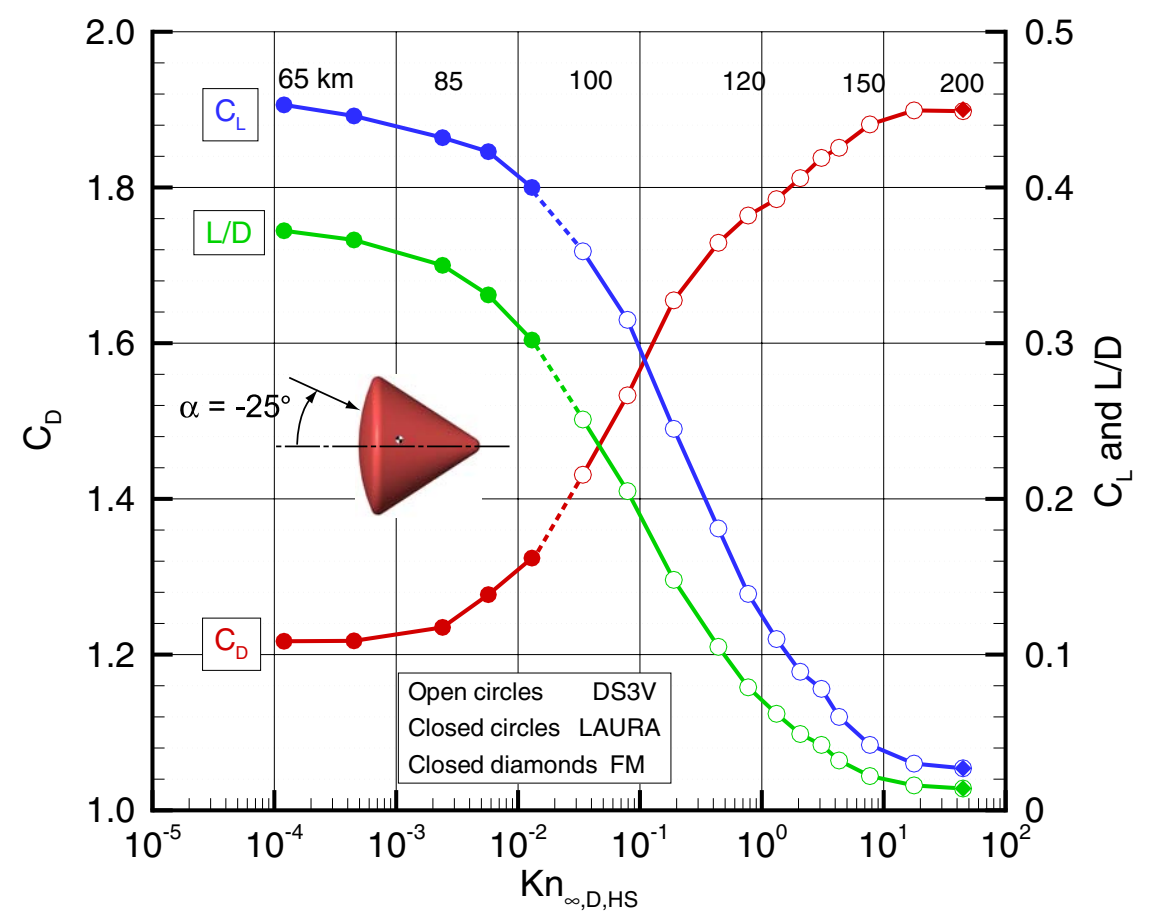

(a) Drag and lift coefficients.

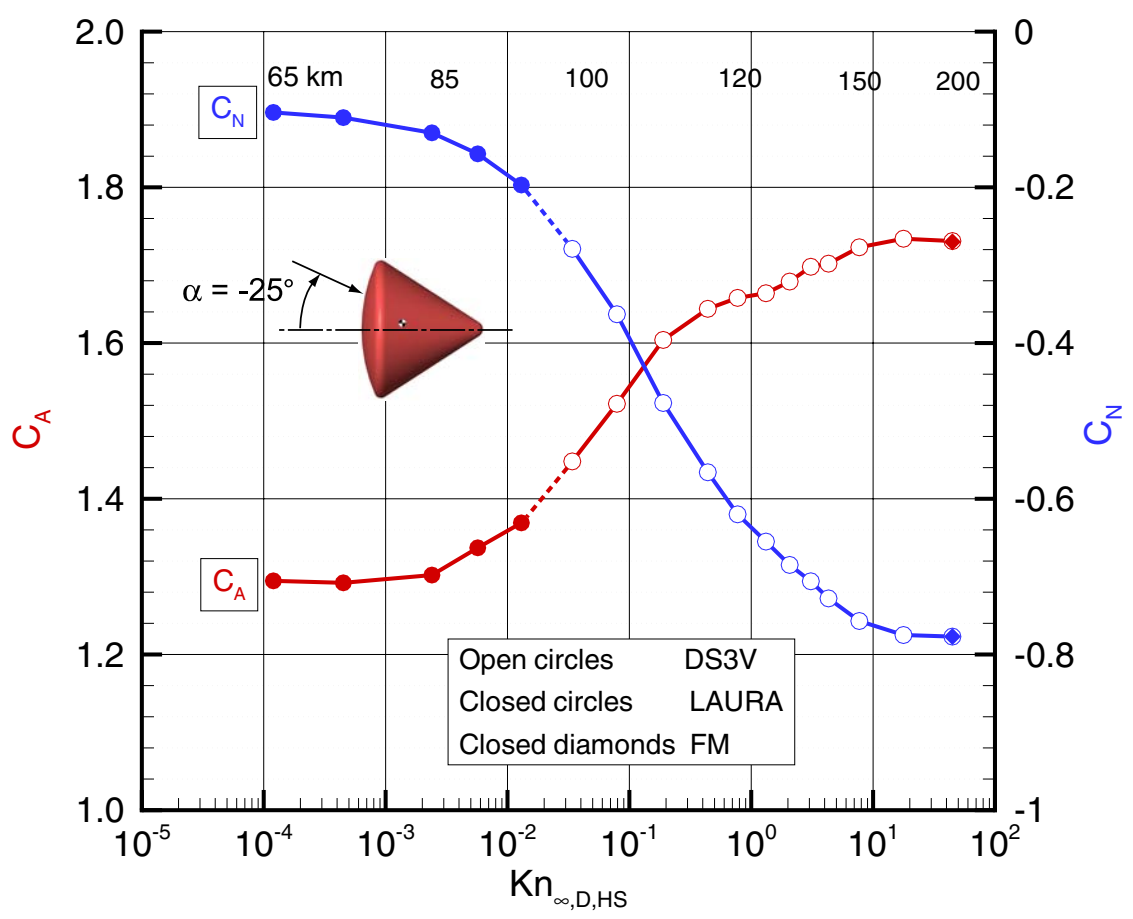

(b) Axial and normal coefficients.

Figure 6. Apollo aerodynamics as a function of rarefaction for an incidence angle of $\mathbf{- 2 5}$ degrees.

14 of 18 


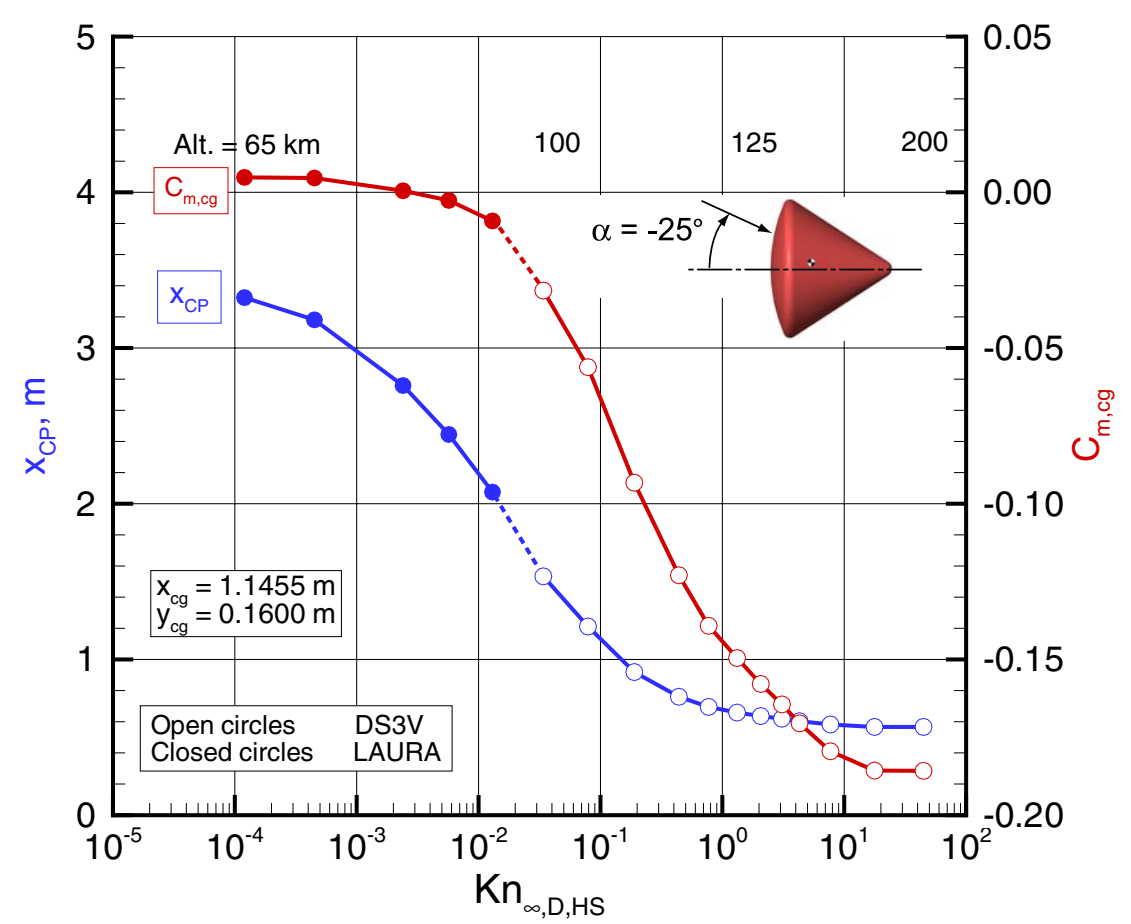

Figure 7. Sensitivity of center of pressure and moment coefficient to rarefaction for $\mathbf{- 2 5}$ degrees angle of incidence.

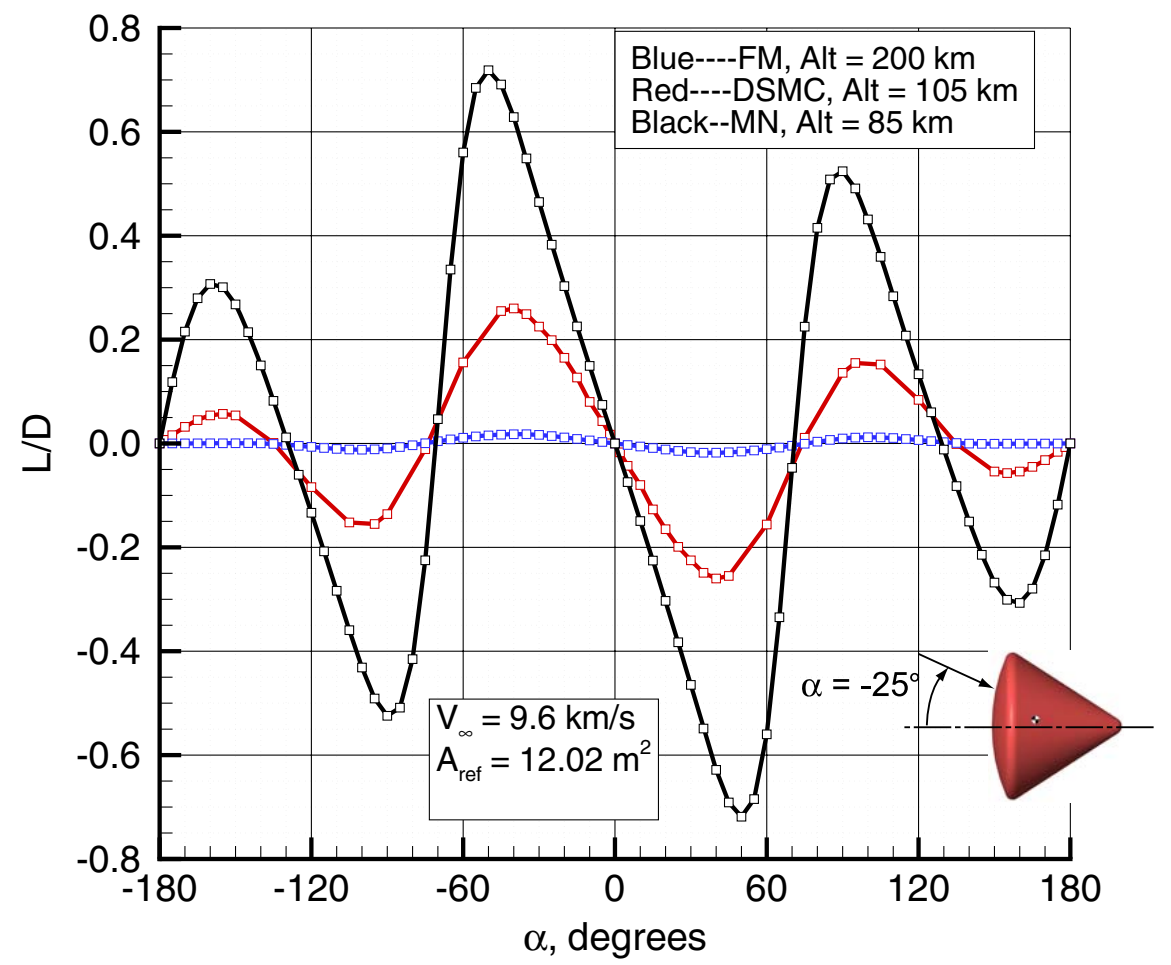

Figure 8. Lift-to-drag (L/D) as a function of incidence for selected altitudes (rarefaction). 


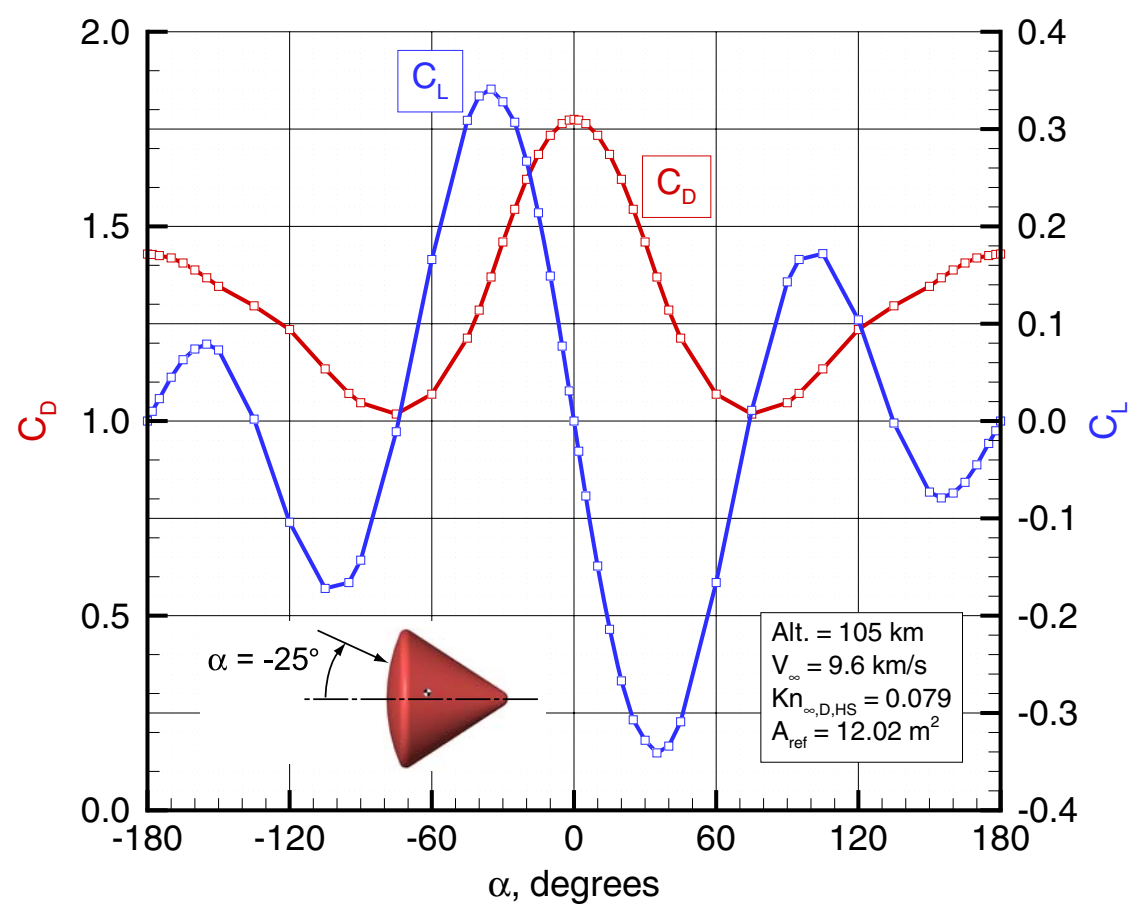

(a) Drag and lift coefficients.

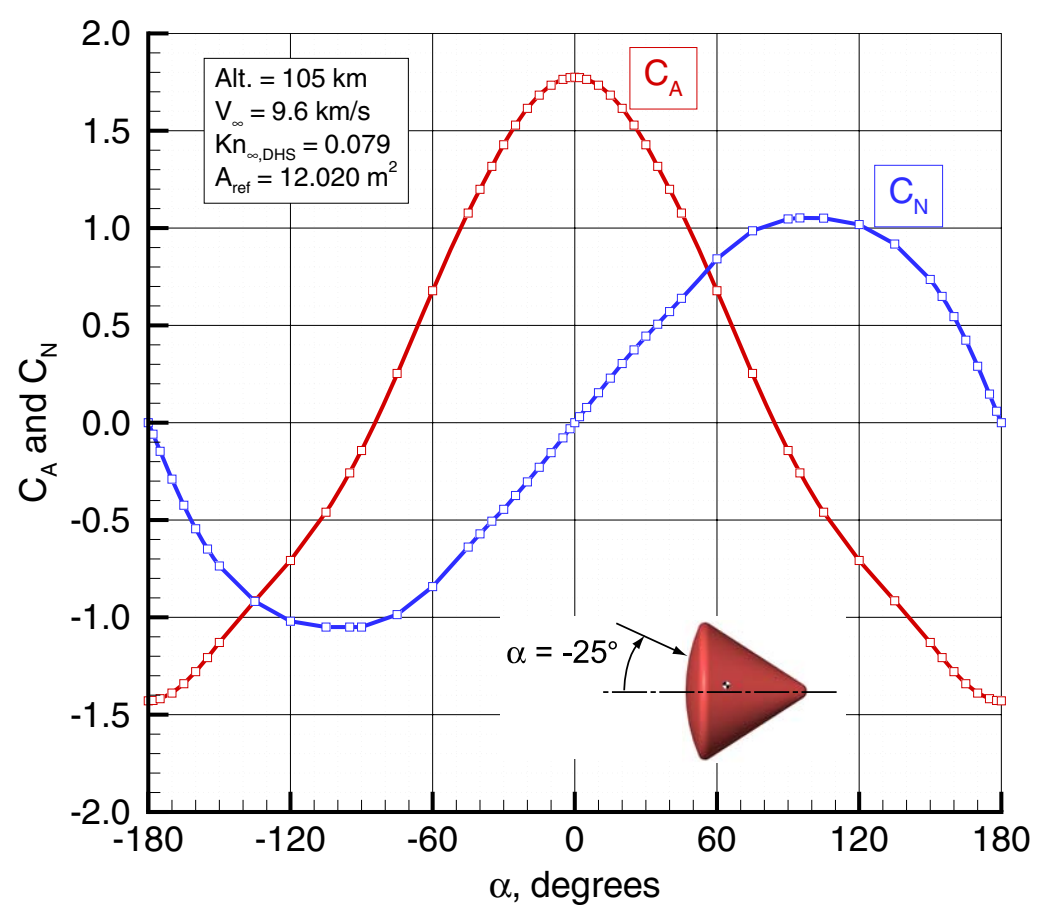

(b) Axial and normal coefficients.

Figure 9. Calculated aerodynamics for Apollo capsule at $105 \mathrm{~km}$ and $9.6 \mathrm{~km} / \mathrm{s}$.

16 of 18 


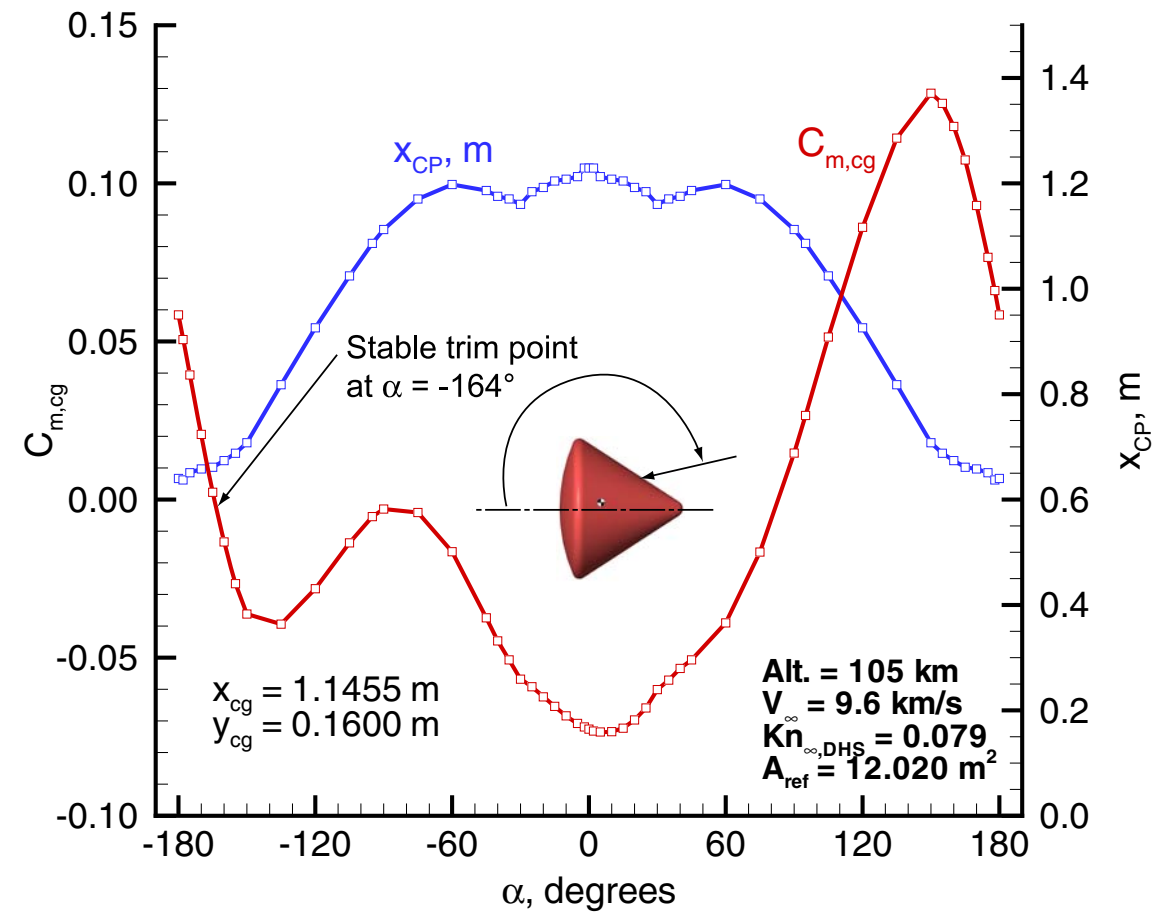

Figure 10. Longitudinal center of pressure location and moment coefficient as a function of incidence. 


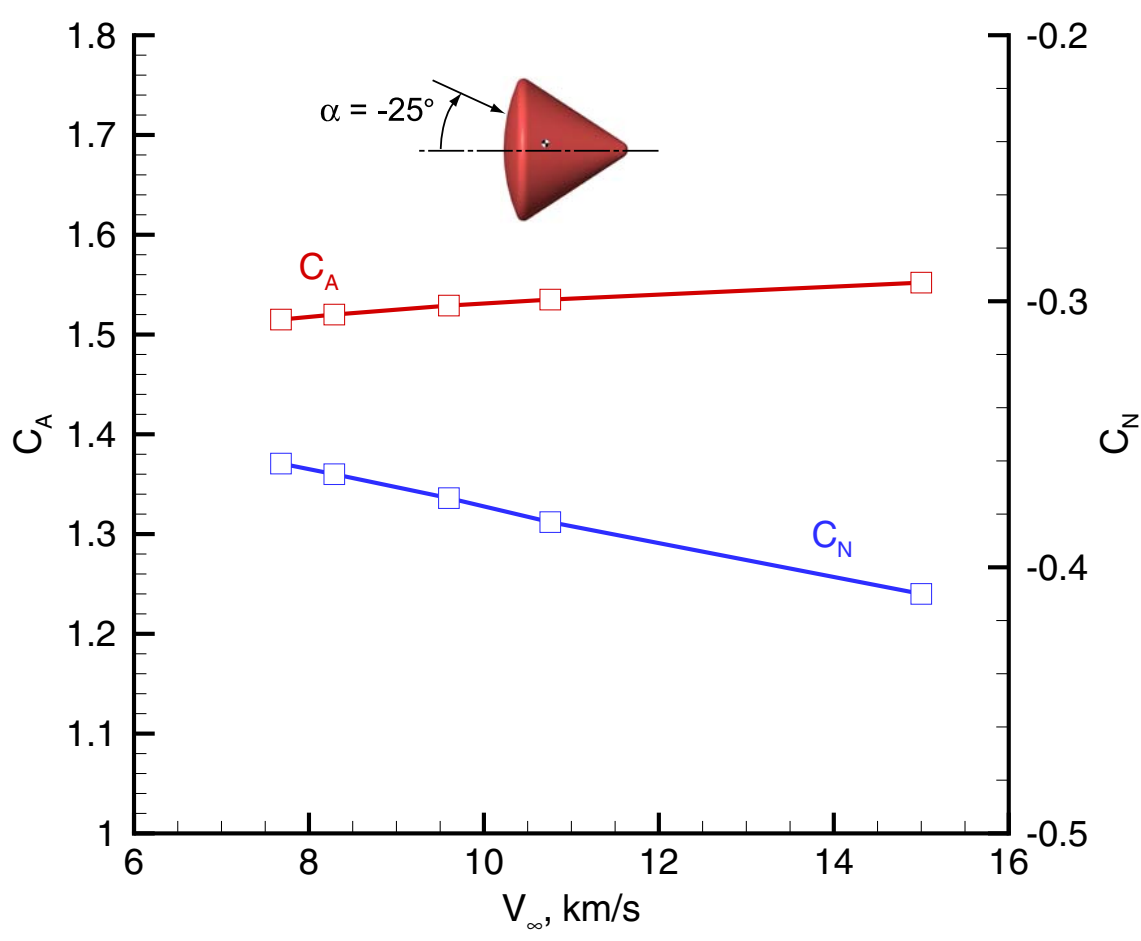

(a) Axial and normal coefficients.

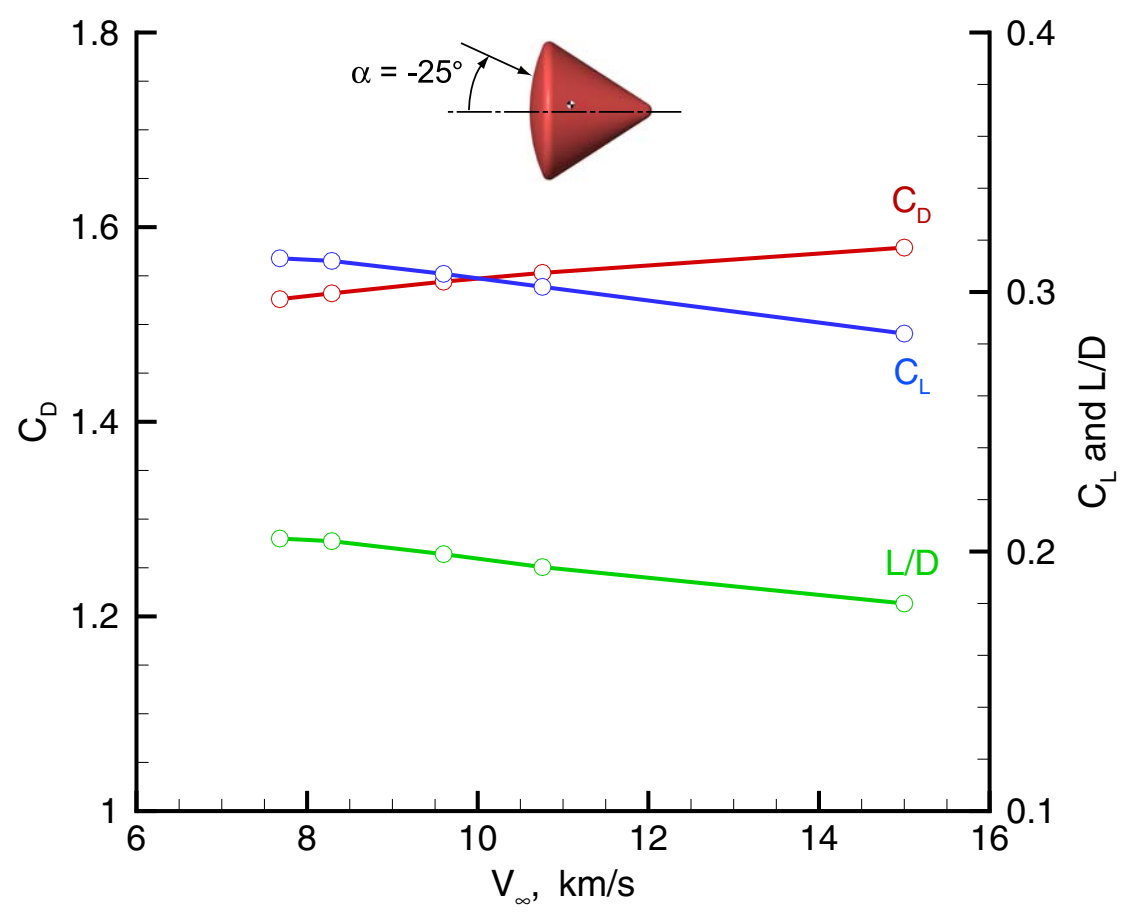

(b) Lift and drag coefficients.

Figure 11. Sensitivity of aerodynamic coefficients to reentry velocity at $105 \mathrm{~km}$.

18 of 18 